\title{
PENENTUAN CADANGAN ASURANSI JIWA BERJANGKA PADA STATUS HIDUP GABUNGAN MENGGUNAKAN METODE PREMIUM SUFFICIENCY
}

\author{
FINTI WARNI, DODI DEVIANTO, RADHIATUL HUSNA \\ Jurusan Matematika, \\ Fakultas Matematika dan Ilmu Pengetahuan Alam, Universitas Andalas, \\ Kampus UNAND Limau Manis Padang, Indonesia, \\ email : fintiwarni.fw@gmail.com
}

\begin{abstract}
Abstrak. Asuransi jiwa yaitu suatu upaya yang dilakukan manusia untuk mengurangi dampak kerugian finansial akibat terjadinya peristiwa yang tidak diinginkan seperti meninggal dunia, kecelakaan, bencana dan lain-lain. Salah satu jenis asuransi jiwa berdasarkan jumlah peserta asuransi adalah asuransi jiwa gabungan. Asuransi jiwa gabungan merupakan asuransi jiwa yang diikuti oleh lebih dari satu peserta asuransi yang namanya berada dalam satu kontrak (joint life status). Asuransi jiwa dibeli dengan pembayaran premi. Diantara jenis-jenis asuransi jiwa, kebanyakan peserta asuransi memilih asuransi jiwa berjangka karena premi asuransi jiwa berjangka paling rendah/murah diantara premi asuransi jiwa lainnya. Sebagian premi harus dicadangkan oleh perusahaan asuransi yang disebut dengan cadangan premi. Cadangan premi diperlukan untuk menutupi klaim peserta asuransi yang dapat terjadi sewaktu-waktu. Cadangan dapat dihitung dengan menggunakan premi kotor yaitu premi bersih ditambah biaya manajemen perusahaan asuransi. Pada metode premium sufficiency, cadangan premi dihitung dengan menggunakan premi kotor sehingga metode ini dapat menjelaskan secara rinci cadangan premi yang harus disediakan oleh perusahaan asuransi.
\end{abstract}

Kata Kunci: Asuransi jiwa berjangka, asuransi jiwa gabungan, premi kotor, cadangan premi, metode premium sufficiency

\section{Pendahuluan}

Pada saat ini banyak masyarakat sudah menyadari akan pentingnya asuransi jiwa, yaitu suatu upaya yang dilakukan manusia untuk mengurangi dampak kerugian finansial akibat terjadinya peristiwa yang tidak diinginkan seperti halnya meninggal dunia, kecelakaan, bencana dan lain-lain. Berdasarkan jumlah peserta asuransi, asuransi jiwa dibagi menjadi dua yaitu asuransi jiwa tunggal dan asuransi jiwa gabungan. Asuransi jiwa gabungan adalah asuransi jiwa yang diikuti oleh lebih dari satu peserta asuransi yang namanya berada dalam satu kontrak (joint life status). Diantara jenis-jenis asuransi jiwa tersebut, kebanyakan peserta asuransi memilih asuransi jiwa berjangka karena premi asuransi jiwa berjangka paling rendah/murah diantara premi asuransi jiwa lainnya. Asuransi jiwa berjangka adalah asuransi dimana uang pertanggungan akan dibayarkan jika peserta asuransi meninggal pada jangka waktu tertentu sesuai dengan kontrak yang telah disetujui [4].

Asuransi jiwa biasa dibeli dengan pembayaran premi. Premi merupakan sejumlah uang yang dibayarkan oleh peserta asuransi kepada perusahaan asuransi seba- 
gai bentuk imbalan jasa atas pengalihan resiko serta kerugian yang sewaktu-waktu mungkin akan diderita oleh peserta asuransi. Premi dibagi menjadi dua, yaitu premi bersih dan premi kotor. Premi bersih adalah premi yang di dalam perhitungannya hanya menggunakan perkiraan tingkat mortalitas dan perkiraan tingkat bunga [1]. Pada asuransi jiwa berjangka, premi untuk peserta asuransi berusia $x$ dan $y$ tahun dengan lama masa pertanggungan $n$ tahun untuk uang pertanggungan sebesar $R$ dapat dinyatakan dengan

$$
A_{x y: \bar{n} \mid}^{\prime}=R\left(\frac{M_{x y}-M_{x+n: y+n}}{D_{x y}}\right) .
$$

Selanjutnya untuk jangka pertanggungan selama $n-t$ tahun, usia peserta asuransi masing-masing $x+t$ dan $y+t$ tahun, dengan $0 \leq t \leq n$ maka premi tunggal bersih dari status hidup gabungan untuk asuransi jiwa berjangka dapat ditulis

$$
A_{x+t: y+t: \overline{n-t \mid}}^{\prime}=R\left(\frac{M_{x+t: y+t}-M_{x+n: y+n}}{D_{x+t: y+t}}\right) .
$$

Sedangkan premi yang dibayarkan pada setiap tahun selama $m$ tahun untuk peserta asuransi berusia $x$ dan $y$ tahun dengan lama masa pertanggungan $n$ tahun untuk uang pertanggungan sebesar $R$ dapat dinyatakan dengan

$$
\begin{aligned}
{ }_{m} P_{x y: \bar{n} \mid}^{\prime} & =R\left(\frac{A_{x y: \bar{n} \mid}^{\prime}}{\ddot{a}_{x y: m \mid}}\right) \\
& =R\left(\frac{M_{x y}-M_{x+n: y+n}}{N_{x y}-N_{x+m: y+m}}\right) .
\end{aligned}
$$

\section{Metode Premium Sufficiency}

Metode premium sufficiency adalah metode perhitungan cadangan premi asuransi berdasarkan asumsi premi kotor [2]. Perhitungan cadangan premium sufficiency dilakukan dengan dasar pengeluaran di waktu yang akan datang ditambahkan dengan biaya manajemen perusahaan asuransi sedangkan dari segi pendapatan premi yang digunakan adalah premi kotor.

Premi kotor merupakan premi bersih ditambahkan biaya loading yaitu biaya penutupan baru polis asuransi $(\alpha)$, biaya pengumpulan premi $(\beta)$ dan biaya pemeliharaan premi $\left(\gamma\right.$ dan $\left.\gamma^{\prime}\right)$, sehingga premi kotor memiliki nilai yang lebih besar daripada premi bersih [1]. Premi kotor asuransi jiwa berjangka $n$ tahun untuk peserta asuransi berusia $x$ dan $y$ tahun, dengan premi tahunan selama $m$ tahun yang dibayarkan diawal untuk uang pertanggungan sebesar Rp 1,- yang dinotasikan dengan ${ }_{m} P_{x y: \overline{1}}^{\prime *}$, sehingga dapat dinyatakan dengan persamaan

$$
{ }_{m} P_{x y: n \mid}^{\prime *}=\frac{1}{(1-\beta)}\left({ }_{m} P_{x y: \overline{1} \mid}^{\prime}+\frac{\alpha}{\ddot{a}_{x y: \bar{m} \mid}}+\gamma+\gamma^{\prime} \frac{\left(\ddot{a}_{x y: \bar{n} \mid}-\ddot{a}_{x y: \bar{m} \mid}\right)}{\ddot{a}_{x y: \bar{m} \mid}}\right) .
$$

Selanjutnya, cadangan prospektif untuk jangka pertanggungan selama $n$ tahun dan masa pembayaran premi selama $m$ tahun dengan usia peserta asuransi masingmasing $x$ dan $y$ tahun yang dinyatakan oleh persamaan

$$
{ }_{t}^{m} V_{x y: \overline{n \mid}}^{\prime}=A_{x+t: y+t: \overline{n-t \mid}}^{\prime}-{ }_{m} P_{x y: \bar{n} \mid}^{\prime} \ddot{a}_{x+t: y+t: \overline{m-t \mid}}
$$


Untuk masa pembayaran premi selama $m$ tahun dengan $t \geqslant m$, artinya perhitungan cadangan dilakukan pada waktu berakhirnya pembayaran premi maka tidak ada lagi pendapatan yang diperoleh, sehingga berlaku [1]

$$
\ddot{a}_{x+t: y+t: \overline{m-t \mid}}=0 \text {. }
$$

Dengan mensubstitusikan $\ddot{a}_{x+t: y+t: \overline{m-t \mid}}=0$ ke Persamaan (2.2) maka cadangan prospektif dinyatakan dengan

$$
\begin{aligned}
{ }_{t}^{m} V_{x y: \bar{n}}^{\prime} & =A_{x+t: y+t: \overline{n-t \mid}}^{\prime}-{ }_{m} P_{x y: \bar{n} \mid}^{\prime} 0 \\
& =A_{x+t: y+t \overline{n-t \mid}}^{\prime} .
\end{aligned}
$$

Pada metode premium sufficiency dilakukan modifikasi dimana perhitungan nilai sekarang dari semua pengeluaran di waktu yang akan datang ditambah dengan biaya loading, yaitu biaya penutupan baru polis asuransi $(\alpha)$, biaya pengumpulan premi $(\beta)$ dan biaya pemeliharaan premi $\left(\gamma\right.$ dan $\left.\gamma^{\prime}\right)$, sehingga nilai sekarang semua pengeluaran di waktu yang akan datang, diperoleh

$$
\begin{aligned}
A= & A_{x+t: y+t: \overline{n-t \mid}}^{\prime}+\beta_{m} P_{x y: \bar{n} \mid}^{\prime *} \ddot{a}_{x+t: y+t: \overline{m-t \mid}}+\gamma \ddot{a}_{x+t: y+t: \overline{m-t \mid}} \\
& +\gamma^{\prime}\left(\ddot{a}_{x+t: y+t: \overline{n-t \mid}}-\ddot{a}_{x+t: y+t: \overline{m-t \mid}}\right),
\end{aligned}
$$

sedangkan untuk nilai sekarang total pendapatan di waktu yang akan datang, premi yang digunakan adalah premi kotor sehingga nilai sekarang total pendapatan di waktu yang akan datang dengan pembayaran premi selama $m$ tahun, diperoleh

$$
P a={ }_{m} P_{x y: n \mid}^{\prime *} \ddot{a}_{x+t: y+t: \overline{m-t \mid}} .
$$

Selanjutnya, untuk menentukan cadangan premium sufficiency asuransi jiwa gabungan berjangka selama $n$ tahun dengan usia peserta asuransi masing-masing $x$ dan $y$ tahun dengan premi tahunan yang dibayarkan diawal selama $m$ tahun dinotasikan dengan ${ }_{t}^{m} V_{x y: n \mid}^{\prime(p s)}$, maka berdasarkan metode prospektif, diperoleh

$$
\begin{aligned}
& { }_{t}^{m} V_{x y: \bar{n} \mid}^{\prime(p s)}=A-P a \\
& =A_{x+t: y+t: \overline{n-t \mid}}^{\prime}+\beta_{m} P_{x y: \bar{n} \mid}^{\prime *} \ddot{a}_{x+t: y+t: \overline{m-t \mid}}+\gamma \ddot{a}_{x+t: y+t: \overline{m-t \mid}} \\
& +\gamma^{\prime}\left(\ddot{a}_{x+t: y+t: \overline{n-t \mid}}-\ddot{a}_{x+t: y+t: \overline{m-t \mid}}\right)-{ }_{m} P_{x y: \bar{n} \mid}^{\prime *} \ddot{a}_{x+t: y+t: \overline{m-t \mid}} \\
& =A_{x+t: y+t: \overline{n-t \mid}}^{\prime}-{ }_{m} P_{x y: \bar{n} \mid}^{\prime *} \ddot{a}_{x+t: y+t: \overline{m-t \mid}}+\beta_{m} P_{x y: \bar{n} \mid}^{\prime *} \ddot{a}_{x+t: y+t: \overline{m-t \mid}} \\
& +\gamma \ddot{a}_{x+t: y+t: \overline{m-t \mid}}+\gamma^{\prime}\left(\ddot{a}_{x+t: y+t: \overline{n-t \mid}}-\ddot{a}_{x+t: y+t: \overline{m-t \mid}}\right) \\
& =A_{x+t: y+t: \overline{n-t \mid}}^{\prime}-(1-\beta){ }_{m} P_{x y: \bar{n} \mid}^{\prime *} \ddot{a}_{x+t: y+t: \overline{m-t \mid}}+\gamma \ddot{a}_{x+t: y+t: \overline{m-t \mid}} \\
& +\gamma^{\prime}\left(\ddot{a}_{x+t: y+t: \overline{n-t \mid}}-\ddot{a}_{x+t: y+t: \overline{m-t \mid}}\right) \text {. }
\end{aligned}
$$


Dengan mensubstitusikan Persamaan (2.1) ke Persamaan (2.5), diperoleh

$$
\begin{aligned}
& { }_{t}^{m} V_{x y: \bar{n} \mid}^{\prime(p s)}=A_{x+t: y+t: \overline{n-t \mid}}^{\prime}-\frac{(1-\beta)}{(1-\beta)}\left({ }_{m} P_{x y: \bar{n} \mid}^{\prime}+\frac{\alpha}{\ddot{a}_{x y: \bar{m} \mid}}+\gamma+\gamma^{\prime} \frac{\left(\ddot{a}_{x y: \bar{n}}-\ddot{a}_{x y: \overline{m l}}\right)}{\ddot{a}_{x y: \bar{m} \mid}}\right), \\
& \ddot{a}_{x+t: y+t: \overline{m-t \mid}}+\gamma \ddot{a}_{x+t: y+t: \overline{m-t \mid}}+\gamma^{\prime}\left(\ddot{a}_{x+t: y+t: \overline{n-t \mid}}-\ddot{a}_{x+t: y+t: \overline{m-t \mid}}\right) \\
& =A_{x+t: y+t: \overline{n-t \mid}}^{\prime}-\left({ }_{m} P_{x y: \overline{n \mid}}^{\prime}+\frac{\alpha}{\ddot{a}_{x y: \bar{m} \mid}}\right) \ddot{a}_{x+t: y+t: \overline{m-t \mid}} \\
& +\gamma^{\prime}\left(\ddot{a}_{x+t: y+t: \overline{n-t \mid}}-\frac{\ddot{a}_{x y: \bar{n} \mid}}{\ddot{a}_{x y: \bar{m} \mid}} \ddot{a}_{x+t: y+t: \overline{m-t \mid}}\right) .
\end{aligned}
$$

Karena premi kotor dipengaruhi oleh tiga kelompok utama biaya, salah satunya adalah biaya pemeliharaan premi selama masa pertanggungan, maka anuitas yang digunakan pada cadangan premium sufficiency ada dua yaitu $\ddot{a}_{x+t: y+t: \overline{m-t \mid}}$ untuk pembayaran premi sampai masa pembayaran berakhir dan $\ddot{a}_{x+t: y+t: \overline{n-t \mid}}$ untuk pemeliharaan premi sampai jangka waktu asuransi berakhir.

Dalam bentuk simbol komutasi, cadangan premium sufficiency dapat dinyatakan dengan

$$
\begin{aligned}
{ }_{t}^{m} V_{x y: n \mid}^{\prime(p s)}= & \frac{M_{x+t: y+t}-M_{x+n: y+n}}{D_{x+t: y+t}}-\left(\frac{M_{x y}-M_{x+n: y+n}+\alpha D_{x y}}{D_{x+t: y+t}}\right) \\
& \left(\frac{N_{x+t: y+t}-N_{x+m: y+m}}{N_{x y}-N_{x+m: y+m}}\right)+\gamma^{\prime}\left(\frac{N_{x+m: y+m}-N_{x+n: y+n}}{D_{x+t: y+t}}\right) \\
& \left(\frac{N_{x y}-N_{x+t: y+t}}{N_{x y}-N_{x+m: y+m}}\right) .
\end{aligned}
$$

Perhitungan cadangan pada Persamaan (2.6) dilakukan dalam masa pembayaran premi $(t<m)$ sedangkan untuk perhitungan cadangan yang dilakukan pada saat tahun ke - $t$ dengan $(t \geq m)$, artinya perhitungan cadangan dilakukan pada saat pembayaran premi berakhir atau setelah masa pembayaran premi maka

$$
\ddot{a}_{x+t: y+t: \overline{m-t \mid}}=0, \quad t \geq m .
$$

Dengan mensubstitusikan Persamaan (2.8) ke Persamaan (2.6), cadangan premium sufficiency asuransi jiwa gabungan berjangka pada tahun ke $-t$ dimana $(t \geq m)$ dinyatakan dengan

$$
{ }_{t}^{m} V_{x y: n \mid}^{\prime(p s)}=A_{x+t: y+t: \overline{n-t \mid}}^{\prime}+\gamma^{\prime}\left(\ddot{a}_{x+t: y+t: \overline{n-t \mid}}\right) .
$$

Selanjutnya Persamaan (2.9) dalam bentuk simbol komutasi dapat dinyatakan dengan

$$
{ }_{t}^{m} V_{x y: n \mid}^{\prime(p s)}=\frac{M_{x+t: y+t}-M_{x+n: y+n}}{D_{x+t: y+t}}+\gamma^{\prime}\left(\frac{N_{x+t: y+t}-N_{x+n: y+n}}{D_{x+t: y+t}}\right) .
$$

\section{Ilustrasi Kasus}

Suatu perusahaan asuransi jiwa menawarkan produk asuransi jiwa berjangka dengan uang pertanggungan yang akan diterima oleh ahli waris sebesar Rp 
10.000.000,- pada akhir tahun kontrak. Jika tingkat bunga yang berlaku adalah 2,5 $\%$ per tahun dengan jangka pertanggungan 20 tahun dan masa pembayaran premi selama 18 tahun untuk pria dan wanita yang memiliki hubungan kekerabatan dan membeli asuransi jiwa (joint life),dengan peserta asuransi sebagai berikut:

(1) Pria berusia 25 tahun dan wanita berusia 20 tahun.

(2) Pria berusia 35 tahun dan wanita berusia 30 tahun.

(3) Pria berusia 45 tahun dan wanita berusia 40 tahun.

Penyelesaian:

Berdasarkan data pada kasus di atas, maka jenis asuransi yang dipilih adalah asuransi jiwa berjangka pada status hidup gabungan untuk asuransi bersama (joint life insurance) dengan menggunakan Tabel Mortalitas Indonesia 2011 dengan suku bunga $(i)=0,025$. Beberapa notasi yang digunakan dalam perhitungan cadangan, yaitu:

(1) Usia pria, misalkan $x$.

(2) Usia wanita, misalkan $y$.

(3) Lama masa pertanggungan, misalkan $n=20$ tahun.

(4) Lama masa pembayaran premi, misalkan $m=18$ tahun.

(5) Uang Pertanggungan, misalkan $R=\mathrm{Rp} 10.000 .000,00$.

(6) Tingkat suku bunga, misalkan $i=2,5 \%=0,025$.

Pada ilustrasi kasus, sebagian premi harus dicadangkan oleh perusahaan asuransi menggunakan metode premium sufficiency, sehingga perusahaan asuransi dapat menggunakan dana tersebut untuk pembayaran klaim di masa yang akan datang. Berikut perhitungan cadangan menggunakan metode premium sufficiency:

(1) Pria berusia 25 tahun dan wanita berusia 20 tahun.

Perhitungan cadangan premi tahunan pada tahun ke - $t$, asuransi jiwa berjangka untuk $x=25$ tahun dan $y=20$ tahun yang memiliki hubungan kekerabatan dengan $n=20$ tahun dan $m=18$ tahun, menggunakan metode premium sufficiency, yaitu dengan menggunakan Persamaan (2.6):

$$
\begin{aligned}
{ }_{t}^{m} V_{25: 20: \overline{20 \mid}}^{\prime(p s)}= & A_{25+t: 20+t: \overline{20-t \mid}}^{\prime}-\left({ }_{m} P_{25: 20: \overline{20 \mid}}^{1}+\frac{\alpha}{\ddot{a}_{25: 20: \overline{18 \mid}}}\right) \ddot{a}_{25+t: 20+t: \overline{18-t \mid}} \\
& +\gamma^{\prime}\left(\ddot{a}_{25+t: 20+t: \overline{20-t \mid}}-\frac{\ddot{a}_{25: 20: \overline{20 \mid}}}{\ddot{a}_{25: 20: \overline{18} \mid}} \ddot{a}_{25+t: 20+t: \overline{18-t \mid}}\right) .
\end{aligned}
$$

Besarnya biaya penutupan baru $(\alpha)$ sebanyak 0,005 dari total uang pertanggungan, yaitu:

$$
\alpha=0,005 \times R p 10.000 .000,00=R p 50.000,00 .
$$

Besarnya biaya pemeliharaan premi setelah masa pembayaran premi berakhir $\left(\gamma^{\prime}\right)$, sebanyak 0.03 dari total uang pertanggungan, yaitu:

$$
\gamma^{\prime}=0,03 \times R p 10.000 .000,00=R p 300.000,00 \text {. }
$$


Selanjutnya akan ditentukan cadangan premium sufficiency pada tahun pertama, yaitu

$$
\begin{aligned}
{ }_{1}^{18} V_{25: 20: \overline{20 \mid}}^{\prime(p s)}= & A_{26: 21: \overline{19 \mid}}^{\prime}-\left({ }_{18} P_{25: 20: \overline{20 \mid}}^{1}+\frac{\alpha}{\ddot{a}_{25: 20: \overline{18 \mid}}}\right) \ddot{a}_{26: 21: \overline{17 \mid}} \\
& +\gamma^{\prime}\left(\ddot{a}_{26: 21: \overline{19 \mid}}-\frac{\ddot{a}_{25: 20: \overline{20 \mid}}}{\ddot{a}_{25: 20: \overline{18 \mid}}} \ddot{a}_{26: 21: \overline{17 \mid}}\right) . \\
= & R p 247.602,07-\left(\operatorname{Rp} 17.304,02+\frac{R p 50.000,00}{14,57}\right) 13,92 \\
& +R p 300.000,00\left(15,18-\frac{15,80}{14,57} 13,92\right) \\
= & R p-15.093,8 .
\end{aligned}
$$

Dengan cara yang sama, diperoleh cadangan premi tahunan dengan metode premium sufficiency untuk pria berusia 35 tahun dan wanita berusia 30 tahun serta pria berusia 45 tahun dan wanita berusia 40 tahun.

Tabel 1. Besarnya cadangan metode premium sufficiency untuk pria berusia 25 tahun dan wanita berusia 20 tahun, pria berusia 35 tahun dan wanita berusia 30 tahun, dan pria berusia 45 tahun dan wanita berusia 40 tahun pada asuransi jiwa berjangka status hidup gabungan dengan jangka waktu pertanggungan selama 20 tahun.

\begin{tabular}{|c|c|c|c|}
\hline$t$ & ${ }_{t}^{18} V_{25: 20: \overline{20 \mid}}^{\prime(p s)}$ & ${ }_{t}^{18} V_{35: 30: \overline{20 \mid}}^{\prime(p s)}$ & ${ }_{t}^{18} V_{45: 40: \overline{20 \mid}}^{\prime(p s)}$ \\
\hline 1 & $-15.093,8$ & $9.640,53$ & $66.362,84$ \\
\hline 2 & $20.567,895$ & $69.222,47$ & $182.610,36$ \\
\hline 3 & $57.162,674$ & $129.105,63$ & $296.396,35$ \\
\hline 4 & $94.714,913$ & $189.313,69$ & $406.936,33$ \\
\hline 5 & $133.150,82$ & $249.480,61$ & $513.760,63$ \\
\hline 6 & $172.100,93$ & $309.237,68$ & $615.842,95$ \\
\hline 7 & $211.484,66$ & $367.827,40$ & $711.868,20$ \\
\hline 8 & $251.415,75$ & $425.060,03$ & $800.610,84$ \\
\hline 9 & $292.106,97$ & $480.837,74$ & $881.485,63$ \\
\hline 10 & $333.387,38$ & $534.586,12$ & $953.863,58$ \\
\hline 11 & $374.987,7$ & $585.815,69$ & $1.017 .082,28$ \\
\hline 12 & $416.635,35$ & $633.745,69$ & $1.070 .352,85$ \\
\hline 13 & $458.149,78$ & $677.485,32$ & $1.112 .466,35$ \\
\hline 14 & $499.538,2$ & $716.214,11$ & $1.142 .201,46$ \\
\hline 15 & $540.429,16$ & $749.270,59$ & $1.158 .453,53$ \\
\hline 16 & $580.445,83$ & $775.501,98$ & $1.159 .872,11$ \\
\hline 17 & $618.829,71$ & $793.524,20$ & $1.145 .076,77$ \\
\hline 18 & $655.370,98$ & $802.074,81$ & $1.112 .311,71$ \\
\hline 19 & $334.121,04$ & $413.988,39$ & $581.305,91$ \\
\hline 20 & 0 & 0 & 0 \\
\hline
\end{tabular}

Nilai cadangan ke -20 tahun untuk ketiga pasangan sama dengan nol. Hal ini berarti bahwa pada saat masa pertanggungan asuransi berakhir, perusahaan asu- 


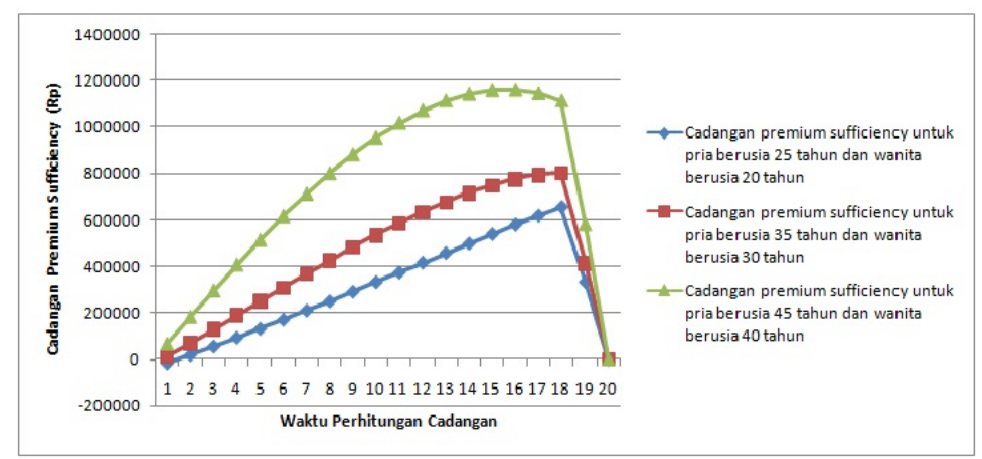

Gambar 1. Grafik perbandingan nilai cadangan premium sufficiency untuk pria berusia 25 tahun dan wanita berusia 20 tahun, pria berusia 35 tahun dan wanita berusia 30 tahun, pria berusia 45 tahun dan wanita berusia 40 tahun.

ransi tidak membayarkan uang pertanggungan kepada peserta asuransi jika peserta asuransi masih hidup sampai masa pertanggungan asuransi berakhir.

Perhitungan cadangan tanpa memperhitungkan biaya manajemen perusahaan asuransi dapat mengakibatkan perusahaan asuransi mengalami kerugian karena cadangan yang diperoleh tidak sesuai dengan perhitungan. Oleh karena itu, perhitungan cadangan menggunakan metode premium sufficiency dapat meminimumkan kemungkinan perusahaan asuransi mengalami kerugian saat terjadi klaim oleh peserta asuransi.

\section{Kesimpulan}

Berdasarkan tujuan yang telah dibuat dalam tugas akhir ini dengan beberapa batasan masalah didapatkan model cadangan asuransi jiwa berjangka pada status hidup gabungan dengan menggunakan metode premium sufficiency sebagai berikut:

(1) Pada saat $t<m$, maka:

$$
\begin{aligned}
{ }_{t}^{m} V_{x y: n \mid}^{\prime(p s)}= & \frac{M_{x+t: y+t}-M_{x+n: y+n}}{D_{x+t: y+t}}-\left(\frac{M_{x y}-M_{x+n: y+n}+\alpha D_{x y}}{D_{x+t: y+t}}\right)\left(\frac{N_{x+t: y+t}-N_{x+m: y+m}}{N_{x y}-N_{x+m: y+m}}\right) \\
& +\gamma^{\prime}\left(\frac{N_{x+m: y+m}-N_{x+n: y+n}}{D_{x+t: y+t}}\right)\left(\frac{N_{x y}-N_{x+t: y+t}}{N_{x y}-N_{x+m: y+m}}\right) .
\end{aligned}
$$

(2) Pada saat $t \geq m$, maka:

$$
{ }_{t}^{m} V_{x y: n \mid}^{\prime(p s)}=\frac{M_{x+t: y+t}-M_{x+n: y+n}}{D_{x+t: y+t}}+\gamma^{\prime}\left(\frac{N_{x+t: y+t}-N_{x+n: y+n}}{D_{x+t: y+t}}\right) .
$$

\section{Daftar Pustaka}

[1] Futami, Takashi. 1993. Matematika Asuransi Jiwa Bagian I. Incorporated Foundation Oriental Life Insurance Cultural Development Center, Tokyo.

[2] Futami, Takashi. 1993. Matematika Asuransi Jiwa Bagian II. Incorporated Foundation Oriental Life Insurance Cultural Development Center, Tokyo. 
Penentuan Cadangan Asuransi Jiwa Berjangka dengan Metode Premium Sufficiency 63

[3] Larson, R. E. A. Gaumnitz. 1951. Life Insurance Mathematics. John Wiley and Sons Inc, New York.

[4] Salim, A. 2007. Asuransi dan Manajemen Resiko. Raja Grafindo Pustaka, Jakarta.

[5] Sembiring, RK. 1986. Buku Materi Pokok Asuransi I. Karunika Universitas Terbuka, Jakarta. 